\title{
Pemberantasan Buta Huruf Al-Qur'an pada warga dan Komunitas Pemulung di Tempat Pembuangan Akhir Sampah (TPA) Kelurahan Karyabaru, Palembang
}

\author{
Sofyan ${ }^{1}$, M Hasbi2 $^{2}$, Muhammad Jhoni Nur ${ }^{2}$ \\ 1,2 Universitas Islam Negeri Raden Fatah Palembang, Indonesia
}

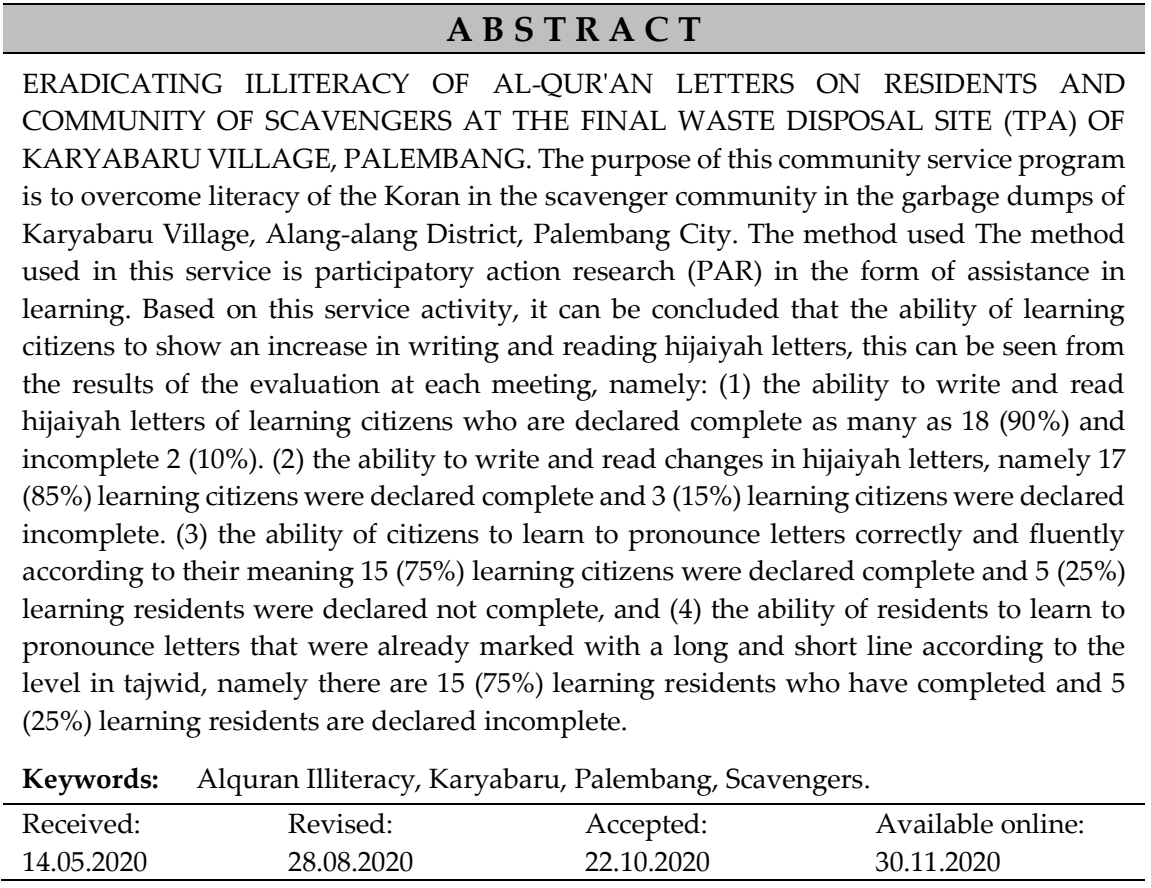

Suggested citation:

Sofyan, Hasbi, M., \& Nur, M. (2020). Pemberantasan buta huruf Al-Qur'an pada warga dan komunitas pemulung di tempat pembuangan akhir sampah (TPA) Kelurahan Karyabaru, Palembang. Jurnal Pengabdian Pada Masyarakat, 5(4), 993-1003. https://doi.org/10.30653/002.202054.663

Open Access I URL: http://ppm.ejournal.id/index.php/pengabdian/article/view/663

\footnotetext{
1 Corresponding Author: Program Studi Pendidikan Agama Islam, FITK Universitas UIN Raden Fatah Palembang; Jl.Prof Zainal Abidin Fikry 3,5 Palembang, Indonesia. Email: Sofyan_uin@radenfatah.ac.id dan mjhoni@radenfatah.ac.id
} 


\section{PENDAHULUAN}

Secara umum di Indonesia, kemampuan membaca Alquran umat islam saat ini tergolong masih lemah dan rendah. Berdasarkan data survey penelitian dinyatakan bahwa hampir 65\%, masyarakat Indonesia Muslim belum bisa membaca Alquran (Huda, 2018; Khairiyah, 2019; Sadiah et al., 2018). Ketidakmapuan masyarakat dalam membaca alquran, akan berdampak terhadap kurangnya masyarakat untuk berintereaksi dengan alquran, merasa malu/minder jika ada taddarus quran dimasjid, dan tidak dapat mentadaburi alquran sebagai pedoman hidup. Sehingga pada akhirnya menyebabkan mereka jauh dari pengalaman nilai-nilai alquran seperti mencuri/merampok,pemakai dan penjual narkoba serta perbuatan negatif lainnya (Jamil, 2018; Romli, 2017; Rusli, 2012). Di samping itu faktor sosial mereka termarginalkan di masyarakat dan secara ekonomi mereka dalam kategori miskin yang membuat mereka tidak peduli terhadap pendidikan agama. Factor-faktor inilah yang menjadi faktor terbesar penyebab buta aksara yang mereka alami (Wahyudi, 2012).

Upaya pemerintah dalam pemberantasan buta huruf Alquran telah dilakukan, yaitu dengan mengeluarkan PP tentang gerakan Masyarakat Maghrib Mengaji (Gemar Mengaji) (Indra, 2016; Sanusi, 2016; Satturi, 2017) dan Pemerintah Kota Palembang pun juga telah mencanangkan program ini. Akan tetapi program mengaji ini belumlah optimal dan belumlah efisien dalam tataran pelaksanaanya di masyarakat (Khairullah \& Zulkarnaini, 2017). Masih ada sebagian golongan masyarakat seperti komunitas pemulung yang belum merasakan akses program ini. Salah satu faktornya adalah ketersedian pengajar yang terbatas dan motivasi mengaji/keagamaan yang rendah bagi komunitas pemulung (Khairullah \& Zulkarnaini, 2017).

Komunitas pemulung juga terdapat di TPA sampah kota Palembang yaitu di daerah Kelurahan Karya Baru Kecamatan Alang-alang Lebar Rt 28. Berdasarkan wawancara yang telah dilakukan, sebagian besar, warga masih banyak yg belum bisa membaca alquran dan sebagian kecil sudah bisa namun masih terbata-bata serta belum paham ilmu tajwid.

Permasalahan-permasalahan tersebut sudah sepatutnya menjadi alarm/perhatian para akademisi muslim. Kalau bukan kita, siapa lagi yang peduli terhadap mereka. Oleh karena itu dalam pengabdian ini, yang menjadi subjek dampingan adalah kominitas pemulung di Tempat Pembuangan Akhir (TPA) Sampah di Kelurahan Karya Baru Palembang. Berdasarkan pembicaraan dengan Lurah setempat dan tokoh masyarakat subjek dampingan, maka persoalan prioritas yang akan ditangani dalam pengabdian ini adalah:

1) Masyarakat subjek dampingan masih belum antusias dalam kegiatan pengajian dan keagamaan sehingga perlu motivasi spiritual bagi mereka.

2) Sebagian besar subjek dampingan masih belum bisa membaca alquran sama sekali dan belum mengenal huruf-huruf hijaiyah

3) Subjek dampingan sebagian kecil sudah bisa membaca alquran namun terbata-bata dan belum sesuai dengan kaidah hukum-hukum tajwid. 


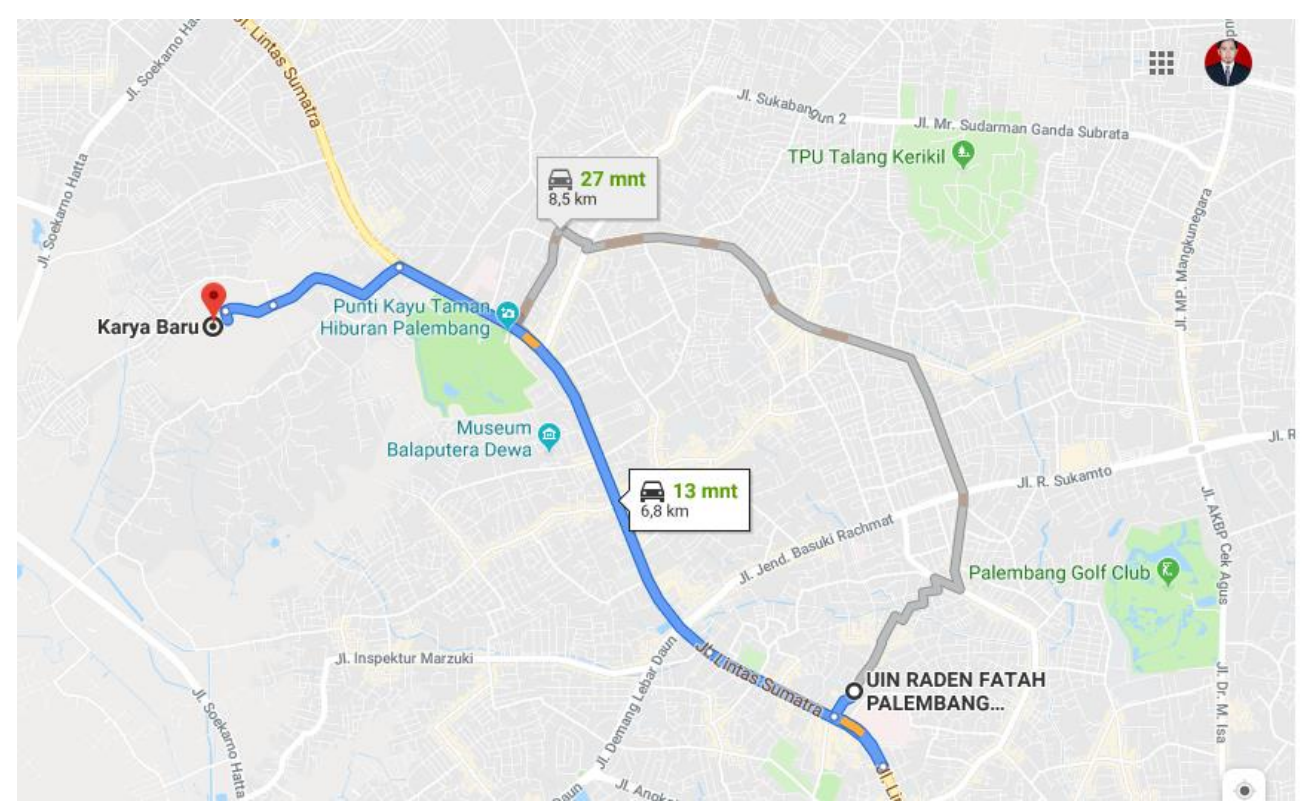

Gambar 1. Peta Lokasi Kegiatan Pengabdian

(Sumber : https://goo.gl/maps/7ADMbW9AJF7bzx6bA)

\section{METODE}

Metode yang akan digunakan dalam pengabdian ini adalah Partisipatory action research (PAR) dalam bentuk pendampingan dalam pembelajaran, yang mana semua pihak yang relevan dilibatkan secara aktif, dalam menganalisis tahapan-tahapan kegiatan yang sedang berlangsung guna melakukan perubahan-perubahan subjek dampingan yang lebih baik lagi (Cherniack et al., 2016; Furbish et al., 2016; Kennedy, 2018; Suwantip \& Witthayawirasak, 2018)

Adapun langkah-langkah yang akan dilaksanakan sebagai berikut:

\section{Persiapan}

Tim pelaksana menyiapkan segala sesuatu untuk kegiatan. Selain itu, tim juga akan berkoordinasi ke ketua RT dan lurah, tokoh masyarakat, dan pengurus masjid setempat, serta Subyek Dampingan dalam rangka persiapan untuk pelaksanaan kegiatan baik jadwal maupun persiapan alat dan bahan dalam kegiatan.

\section{Sosialisasi}

Tim pelaksana akan melakukan silaturahmi ke rumah-rumah warga subjek dampingan sebagai sosialisasi awwalan untuk membangun kedekatan emosional dan sosial. Selanjutnya subjek dampingan akan diundang bersama ketua RT, pengurus masjid dan tokoh masyarakat untuk dikumpulkan guna diberikan penjelasan sosialisasi lanjutan kegiatan program. Kegiatan ini akan dilaksanakan dengan metode ceramah dan tanya jawab. Tempat kegiatan di Masjid An-Nurnia yang berada di dekat komunitas subjek dampingan. 


\section{Pelatihan/Pendampingan}

Pada tahap ini dilaksanakan dalam bentuk pelatihan dan pendampingan secara klasikal dan individual dengan metode Iqro'. Di pertemuan perdana dilakukan secara klasikal (keselurahan) disinilah dilakukan pendekatan agamis dan spritualitas. Adapun targetnya adalah memotivasi peserta agar dapat meningkatkan diri menjadi lebih baik seorang muslim dan semangat dalam belajar alquran. Setelah itu secara individual, masing-masing peserta maju menghadap ustadz (pengajar) sementara yang lain mempersiapkan diri sebelum mendapat giliran maju menghadap ustadz. Ada sekitar 50 subjek dampingan yang akan dibagi dalam lima kelompok. Masing-masing kelompok akan ditangani oleh seorang pengajar/guru/ustadz yang terdiri dari tim pengabdian dan beberapa mahasiswa yang telah ditunjuk dan direkomendasikan untuk menjadi pengajar quran dalam program ini. Tutor/ pengajar dari mahasiswa akan dites bacaan alqurannya untuk memastikan bahwa mahasiswa tersebut memenag baik bacaan alqurannya.

\section{Evaluasi}

Tim pelaksana akan mengecek perkembangan kemampuan baca alquran setiap bulan walaupun setiap akhir pertemuan dilakukan evaluasi serta melalui kartu mengaji peserta. Pada tahap ini dilakukan penilaian kemampuan membaca alquran peserta dengan lembar penialaian guna menilai keberhasilan program dan bahan evaluasi ke depan.

\section{Finishing Program}

Tim pelaksana dan peserta akan berdiskusi tentang sejauh mana tingkat keberhasilan program, kendala atau masalah yang dihadapai selama kegiatan berlangsung, dan saran serta tindak lanjut setelah program dengan membentuk komunitas quran permanen.

\section{HASIL DAN PEMBAHASAN}

Kegiatan pengabdian ini bekerja sama dengan Kelurahan Karya Baru, RT 28 dan warga masyarakat lainnya yang berada di sekitar Masjid An-Nurnia. Tim Pelaksana terdiri dari dua orang dosen dan 4 orang mahasiswa. Kegiatan ini dilaksanakan pada awal bulan Februari sampai dengan September 2020. Lima tahapan dalam kegiatan Pengabdian ini yaitu sebagai berikut ini :

\section{Persiapan}

Pada tahap persiapan kegiatan pengabdian ini telah melaksanakan koordinasi dengan anggota tim lainnya pada bulan Desember 2020. Koordinasi meliputi jadwal kunjungan ke subyek dampingan dan agenda apa saja yang akan dibicarakan dengan subjek dampingan. Setelah persiapan cukup matang, tim pelaksana berkujung ke subjek dampingan guna melakukan koordinasi kegiatan pengabdian. Hasil dari koordinasi dengan subjek dampingan disepakati bahwa kegiatan sosialisasi dilaksanakan pada 
hari Sabtu, 22 Februari 2020. Subjek dampingan mempersiapkan peserta, ruangan, dan sound system untuk kegiatan sosialisasi tersebut.

\section{Sosialisasi}

Tim pelaksana akan melakukan silaturahmi ke rumah-rumah warga subjek dampingan sebagai sosialisasi awwalan untuk membangun kedekatan emosional dan sosial. Selanjutnya subjek dampingan akan diundang bersama ketua RT, pengurus masjid dan tokoh masyarakat untuk dikumpulkan guna diberikan penjelasan sosialisasi lanjutan kegiatan program. Kegiatan ini akan dilaksanakan dengan metode ceramah dan tanya jawab. Tempat kegiatan di Masjid An nur nia yang berada di dekat komunitas subjek dampingan. Adapun kegiatannya dilakukan di Masjid An nur nia Sabtu tanggal 22 Februari 2020 ba'da maghrib.

Berikut ini foto kegiatan sosialisasai kepada masyarakat subjek dampingan, yaitu warga komunitas dan warga masyarakat di sekitar masjid An nur nia Kelurahan Karyabaru:

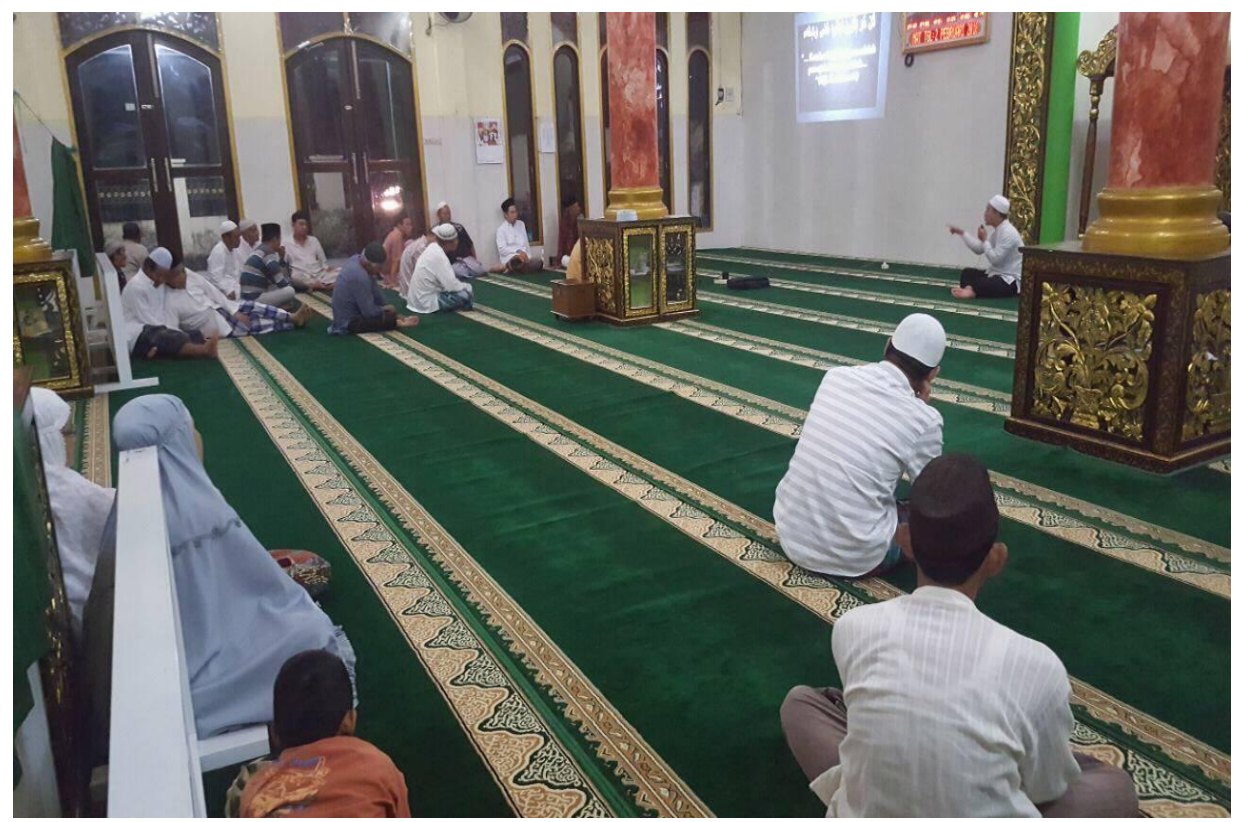

Gambar 2. Foto-foto Kegiatan Sosialisasi Kegiatan

Pelatihan/Pendampingan

Pada tahap ini dilaksanakan dalam bentuk pelatihan dan pendampingan secara klasikal dan individual dengan metode Iqro'. Di pertemuan perdana dilakukan secara klasikal (keselurahan) disinilah dilakukan pendekatan agamis dan spritualitas dengan protocol kesehatan. Adapun targetnya adalah memotivasi peserta agar dapat meningkatkan diri menjadi lebih baik seorang muslim dan semangat dalam belajar alquran. Setelah itu secara mempersiapkan diri sebelum mendapat giliran maju menghadap ustadz. Ada sekitar 30 subjek dampingan yang berhasil dijaring dan dibagi dalam lima kelompok. Masing-masing kelompok ditangani oleh seorang pengajar/guru/ustadz yang terdiri dari tim pengabdian dan beberapa mahasiswa yang telah ditunjuk dan direkomendasikan untuk menjadi pengajar quran dalam program 
ini. Tutor/ pengajar dari mahasiswa akan dites bacaan alqurannya untuk memastikan bahwa mahasiswa tersebut memang baik bacaan alqurannya.

\section{Evaluasi Kegiatan}

Pada Tahap ini tim pengabdi melakukan evaluasi dengan cara pengecekan perkembangan kemampuan baca alquran setiap bulan walaupun setiap akhir pertemuan serta melalui kartu mengaji peserta. Pada tahap ini dilakukan penilaian kemampuan membaca alquran peserta dengan lembar penialaian guna menilai keberhasilan program dan bahan evaluasi ke depan. Berikut ini foto kegiatan evaluasi:

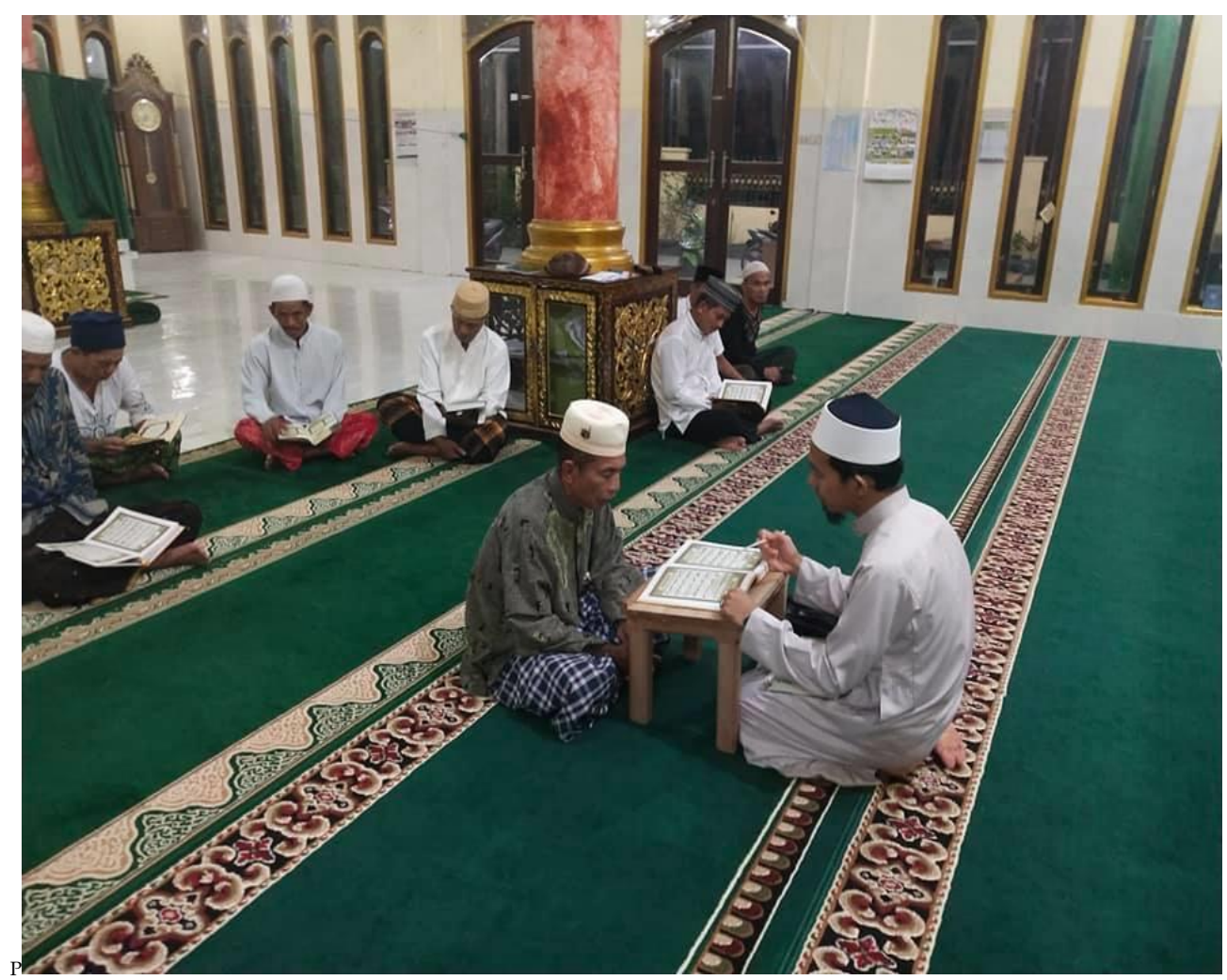

Gambar 3. Saat Evaluasi bacaan Peserta

Untuk melihat keberhasilan pelaksanaan program ini, maka dilakukan evaluasi. Evaluasi dilaksanakan dengan memberikan tes lisan dan tulisan setelah proses pertemuan/pembelajaran. Adapun tes tersebut dikatakan berhasil/tuntas jika secara individual memperoleh nilai $\geq 70 \%$ dan ketuntasan secara klasikal jika mendapatkan $\geq 70 \%$.

Pertemuan pertama dilaksanakan selama 120 menit yaitu 90 menit dipergunakan untuk melaksanakan proses pembelajaran tentang materi menulis dan membaca huruf hijaiyah dan 30 menit selanjutnya dipergunakan untuk melakukan evaluasi yaitu dengan meminta warga belajar menulis dan membaca huruf hijaiyah. Adapun hasil penilaian kemampuan warga belajar menulis dan membaca huruf hijaiyah pada pertemuan pertama ini pada Tabel 1. 
Tabel 1. Kemampuan Warga belajar menulis dan membaca Huruf Hijaiyyah

\begin{tabular}{|c|c|c|c|}
\hline No. & Peserta & Nilai & Kriteria \\
\hline 1 & warga 1 & 71 & Tuntas \\
\hline 2 & warga 2 & 78 & Tuntas \\
\hline 3 & warga 3 & 83 & Tuntas \\
\hline 4 & warga 4 & 84 & Tuntas \\
\hline 5 & warga 5 & 100 & Tuntas \\
\hline 6 & warga 6 & 64 & Tidak Tuntas \\
\hline 7 & warga 7 & 90 & Tuntas \\
\hline 8 & warga 8 & 81 & Tuntas \\
\hline 9 & warga 9 & 79 & Tuntas \\
\hline 10 & warga 10 & 81 & Tuntas \\
\hline 11 & warga 11 & 93 & Tuntas \\
\hline 12 & warga 12 & 90 & Tuntas \\
\hline 13 & warga 13 & 98 & Tuntas \\
\hline 14 & warga 14 & 98 & Tuntas \\
\hline 15 & warga 15 & 100 & Tuntas \\
\hline 16 & warga 16 & 100 & Tuntas \\
\hline 17 & warga 17 & 94 & Tuntas \\
\hline 18 & warga 18 & 61 & Tidak Tuntas \\
\hline 19 & warga 19 & 95 & Tuntas \\
\hline 20 & warga 20 & 91 & Tuntas \\
\hline
\end{tabular}

Berdasarkan data hasil kemampuan menulis dan membaca huruf hijaiyah di atas, dapat disebutkan bahwa jumlah warga belajar yang dinyatakan tuntas sebanyak 18 (90\%) dan tidak tuntas 2 (10\%). Pertemuan kedua, membicarakan materi perubahan huruf hijaiyah. Setelah pelaksanaan pembelajaran, selanjutnya dilakukan uji kemampuan menulis dan membaca perubahan huruf hijaiyah. Hasilnya seperti pada Tabel 2.

Tabel 2. Kemampuan Warga Belajar Membaca Alquran

\begin{tabular}{llcl}
\hline No. & Peserta & Nilai Kemampuan Membaca & Kriteria \\
\hline 1 & warga 1 & 55 & Tidak Tuntas \\
\hline 2 & warga 2 & 71 & Tuntas \\
\hline 3 & warga 3 & 78 & Tuntas \\
\hline 4 & warga 4 & 81 & Tuntas \\
\hline 5 & warga 5 & 88 & Tuntas \\
\hline 6 & warga 6 & 56 & Tidak Tuntas \\
\hline 7 & warga 7 & 89 & Tuntas \\
\hline 8 & warga 8 & 78 & Tuntas \\
\hline 9 & warga 9 & 74 & Tuntas \\
\hline 10 & warga 10 & 78 & Tuntas \\
\hline 11 & warga 11 & 90 & Tuntas \\
\hline 12 & warga 12 & 84 & Tuntas \\
\hline 13 & warga 13 & 93 & Tuntas \\
\hline
\end{tabular}




\begin{tabular}{llcl}
\hline No. & Peserta & Nilai Kemampuan Membaca & Kriteria \\
\hline 14 & warga 14 & 89 & Tuntas \\
\hline 15 & warga 15 & 90 & Tuntas \\
\hline 16 & warga 16 & 84 & Tuntas \\
\hline 17 & warga 17 & 88 & Tuntas \\
\hline 18 & warga 18 & 55 & Tidak Tuntas \\
\hline 19 & warga 19 & 86 & Tuntas \\
\hline 20 & warga 20 & 86 & Tuntas \\
\hline
\end{tabular}

Tabel 2 memperlihatkan kemampuan menulis dan membaca perubahan huruf hijaiyah yaitu 17 (85\%) warga belajar dinyatakan tuntas dan $3(15 \%)$ warga belajar dinyatakan tidak tuntas. Materi melafalkan huruf-huruf dengan benar dan fasih sesuai dengan makhrajnya di belajarkan pada pertemuan ketiga. Pertemuan ketiga ini dipergunakan untuk melaksanakan proses pembelajaran tentang materi melafalkan huruf-huruf dengan benar dan fasih sesuai dengan makhrajnya dan 30 menit selanjutnya dipergunakan untuk melakukan evaluasi yaitu dengan meminta warga belajar melafalkan huruf-huruf dengan benar dan fasih sesuai dengan makhrajnya. Adapun hasil evaluasi pada Tabel 3.

Tabel 3. Kemampuan warga Melafalkan hijaiyyah sesuai makhrajnya

\begin{tabular}{llll}
\hline No & Peserta & Nilai & Kriteria \\
\hline 1 & warga 1 & 50 & Tidak Tuntas \\
\hline 2 & warga 2 & 58 & Tidak Tuntas \\
\hline 3 & warga 3 & 70 & Tuntas \\
\hline 5 & warga 4 & 78 & Tuntas \\
\hline 6 & warga 5 & 80 & Tuntas \\
\hline 7 & warga 6 & 48 & widak Tuntas \\
\hline 8 & warga 8 & 85 & Tuntas \\
\hline 9 & warga 9 & 78 & Tuntas \\
\hline 10 & warga 10 & 60 & Tuntas \\
\hline 11 & warga 11 & 80 & Tidak Tuntas \\
\hline 12 & warga 12 & 78 & Tuntas \\
\hline 13 & warga 13 & 88 & Tuntas \\
\hline 15 & warga 14 & 85 & Tuntas \\
\hline 16 & warga 15 & 73 & Tuntas \\
\hline 17 & warga 16 & 78 & Tuntas \\
\hline 18 & warga 18 & 85 & Tuntas \\
\hline 19 & warga 19 & 73 & Tidak Tuntas \\
\hline 20 & warga 20 & 70 & Tuntas \\
\hline
\end{tabular}

Kemampuan warga belajar melafalkan huruf-huruf dengan benar dan fasih sesuai dengan makhrajnya diperlihatkan pada tabel 4.3 di atas dengan rincian bahwa 15 (75\%) warga belajar dinyatakan tuntas dan $5(25 \%)$ warga belajar dinyatakan belom tuntas. 
Pertemuan ke empat membicarakan materi tentang melafazkan huruf-huruf yang sudah diberi tanda baris panjang pendek sesuai dengan kadar dalam tajwid. Kemampuan warga belajar memahami materi ini adalah sebagai berikut:

Tabel 4. Kemampuan warga melafazkan hijaiyyah sesuai tajwid

\begin{tabular}{|c|c|c|c|}
\hline No & Peserta & Nilai & Kriteria \\
\hline 1 & warga 1 & 48 & Tidak Tuntas \\
\hline 2 & warga 2 & 48 & Tidak Tuntas \\
\hline 3 & warga 3 & 70 & Tuntas \\
\hline 4 & warga 4 & 73 & Tuntas \\
\hline 5 & warga 5 & 75 & Tuntas \\
\hline 6 & warga 6 & 50 & Tidak Tuntas \\
\hline 7 & warga 7 & 83 & Tuntas \\
\hline 8 & warga 8 & 73 & Tuntas \\
\hline 9 & warga 9 & 70 & Tuntas \\
\hline 10 & warga 10 & 53 & Tidak Tuntas \\
\hline 11 & warga 11 & 73 & Tuntas \\
\hline 12 & warga 12 & 75 & Tuntas \\
\hline 13 & warga 13 & 80 & Tuntas \\
\hline 14 & warga 14 & 75 & Tuntas \\
\hline 15 & warga 15 & 70 & Tuntas \\
\hline 16 & warga 16 & 73 & Tuntas \\
\hline 17 & warga 17 & 78 & Tuntas \\
\hline 18 & warga 18 & 50 & Tidak Tuntas \\
\hline 19 & warga 19 & 70 & Tuntas \\
\hline 20 & warga 20 & 70 & Tuntas \\
\hline
\end{tabular}

Tabel 4 menyebutkan ada 15 (75\%) warga belajar yang tuntas atau dianggap sudah mampu melafazkan huruf-huruf yang sudah diberi tanda baris panjang pendek sesuai dengan kadar dalam tajwid dan $5(25 \%)$ warga belajar dinyatakan tidak tuntas atau belum mampu melafazkan huruf-huruf yang sudah diberi tanda baris panjang pendek sesuai dengan kadar dalam tajwid.

\section{Finishing Program}

Melalui hasil pelaksanaan pengabdian ini menunjukkan bahwa warga belajar menunjukan peningkatan kemampuan dalam menulis dan membaca huruf hijaiyah, hal ini sesuai dengan hasil evaluasi di tiap-tiap pertemuan. Dikatakan ada peningkatan, karena sebelum pelaksanaan kegiatan pengabdian kemampuan warga belajar dalam menulis dan membaca huruf hijaiyah tergolong rendah. Selama proses pembelajaran terjadi banyak perubahan kemampuan warga belajar, beberapa ada yang mengalami perkembangan pesat dan ada juga yang masih terhambat yaitu tidak tuntas. Kendalakendala yang paling sering terjadi adalah kendala penglihatan yang sudah tidak normal karena faktor usia dan ingatan.

Tim pelaksana dan peserta akan berdiskusi tentang sejauh mana tingkat keberhasilan program, kendala atau masalah yang dihadapai selama kegiatan 
berlangsung adalah beberapa peserta tidak bisa mengikuti kegiatan secara full karena kesibukan peserta dan juga ada perasaan minder karena masih belum bisa membaca iqro'. Saran serta tindak lanjut setelah program atas permasalahan ini dengan membentuk komunitas quran permanen sebagai bentuk kegiatan dakwah masjid an nur nia.

\section{SIMPULAN}

Berdasarkan hasil kegiatan ini, dapat disimpulan bahwa kemampuan warga belajar menunjukan peningkatan dalam menulis dan membaca huruf hijaiyah, hal ini dilihat dari hasil evaluasi di tiap-tiap pertemuan yaitu: 1) kemampuan menulis dan membaca huruf hijaiyah warga belajar yang dinyatakan tuntas sebanyak 18 (90\%) dan tidak tuntas $2(10 \%) ; 2)$ kemampuan menulis dan membaca perubahan huruf hijaiyah yaitu $17(85 \%)$ warga belajar dinyatakan tuntas dan $3(15 \%)$ warga belajar dinyatakan tidak tuntas; 3$)$ kemampuan warga belajar melafalkan huruf-huruf dengan benar dan fasih sesuai dengan makhrajnya $15(75 \%)$ warga belajar dinyatakan tuntas dan $5(25 \%)$ warga belajar dinyatakan belom tuntas; dan 4) kemampuan warga belajar melafazkan huruf-huruf yang sudah diberi tanda baris panjang pendek sesuai dengan kadar dalam tajwid yaitu ada $15(75 \%)$ warga belajar yang tuntas dan $5(25 \%)$ warga belajar dinyatakan tidak tuntas.

\section{Ucapan Terima Kasih}

Terimakasih kami haturkan kepada Universitas Islam Negeri Raden Fatah Palembang, cq. Lembaga Penelitian dan Pengabdian kepada Masyarakat atas dukungan dan bantuan pendanaanya.

\section{REFERENSI}

Cherniack, M., Dussetschleger, J., Dugan, A., Farr, D., Namazi, S., El Ghaziri, M., \& Henning, R. (2016). Participatory action research in corrections: The HITEC 2 program. Applied Ergonomics, 53, 169-180. https://doi.org/10.1016/j.apergo.2015.09.011

Furbish, D. S., Bailey, R., \& Trought, D. (2016). Using participatory action research to study the implementation of Career Development Benchmarks at a New Zealand university. International Journal for Educational and Vocational Guidance, 16(1), 153-167. https://doi.org/10.1007/s10775-015-9295-5

Huda, K. (2018). Teaching material development "Practical guidelines for reading AlQur'an" in learning Al-Qur'an at griya Al-Qur'an of Surabaya. Studia Religia: Jurnal Pemikiran dan Pendidikan Islam, 2(2), 1-19.

Indra, D. (2016). Pelaksanaan manajemen program gerakan masyarakat magrib mengaji di Provinsi Sumatera Barat (Studi komparatif di tiga daerah). Al-Fikrah: Jurnal Manajemen Pendidikan, 2(2), 101-114.

Jamil, N. (2018). Pengaruh bimbingan melalui tadabur alquran dalam meningkatkan spiritualitas remaja: Studi penelitian di lembaga pembinaan khusus anak kelas II Bandung [PhD Thesis]. Bandung: UIN Sunan Gunung Djati Bandung. 
Kennedy, H. (2018). How adults change from facilitating youth participatory action research: Process and outcomes. Children and Youth Services Review, 94, 298-305. https://doi.org/10.1016/j.childyouth.2018.10.010

Khairiyah, M. (2019). Motivasi Belajar Membaca Alquran Pada Mahasiswa Yang Buta Baca Alquran Di Fakultas Psikologi Universitas Muhammadiyah Surakarta [PhD Thesis]. Surakarta: Universitas Muhammadiyah Surakarta.

Khairullah, M. R., \& Zulkarnaini, Z. (2017). Evaluasi peraturan daerah nomor 2 tahun 2013 tentang gerakan masyarakat maghrib mengaji di Kabupaten Kampar. Jurnal Online Mahasiswa Fakultas Ilmu Sosial dan Ilmu Politik Universitas Riau, 4(1), 1-15.

Romli, A. S. M. (2017). Pesan Alquran tentang akhlak (Analisis hermeneutis double movement Fazlur Rahman terhadap QS al-Hujurat Ayat 11-13). Diya Al-Afkar: Jurnal Studi al-Quran Dan al-Hadis, 5(2), 453-476.

Rusli, A. R. (2012). Korelasi perbuatan dosa dengan azab yang diturunkan Allah dalam perspektif Alquran. Journal Analytica Islamica, 1(2), 308-317.

Sadiah, S., Maya, R., \& Wahidin, U. (2018). Implementasi model pembelajaran dalam pemberantasan buta huruf Alquran di majelis taklim Nurul Hikmah Kampung Situ Uncal Desa Purwasari Kecamatan Dramaga Kabupaten Bogor. Prosa PAI: Prosiding Al Hidayah Pendidikan Agama Islam, 1(1), 1-18.

Sanusi, M. (2016). Pengawasan terhadap pelaksanaan peraturan daerah nomor 2 tahun 2013 tentang gerakan masyarakat magrib mengaji di Desa Mayang Pongkai Kecamatan Kampar Kiri Tengah Kabupaten Kampar [PhD Thesis]. Pekanbaru: Universitas Islam Negeri Sultan Syarif Kasim Riau.

Satturi. (2017). Implementasi gemar mengaji dalam pembinaan baca tulis Al-Qur'an perspektif pendidikan Islam di Kecamatan Marioriwawo Kabupaten Soppeng. Inspiratif Pendidikan, 6(2), 336-343. https://doi.org/10.24252/ip.v6i2.5764

Suwantip, N., \& Witthayawirasak, B. (2018). Using participatory action research for injury prevention in child development centers, Suratthani province. Kasetsart Journal of Social Sciences, 39(1), 98-104. https://doi.org/10.1016/j.kjss.2017.12.003

Wahyudi, A. T. (2012). Pengaruh faktor sosial dan ekonomi orang tua terhadap buta aksara anak usia sekolah di Kecamatan Sumber Wringin Kabupaten Bondowoso. Swara Bhumi, 1(2), 1-7.

\section{Copyright and License}

This is an open access article distributed under the terms of the Creative Commons Attribution 4.0 International License, which permits unrestricted use, distribution, and reproduction in any medium, provided the original work is properly cited.

(C) 2020 Sofyan, M Hasbi, Muhammad Jhoni Nur. 